\title{
Time to compile: A performance installation as human-robot interaction study examining self-evaluation and perceived control
}

https://doi.org/10.1515/pjbr-2019-0024

Received April 1, 2019; accepted July 11, 2019

\begin{abstract}
Embodied art installations embed interactive elements within theatrical contexts and allow participating audience members to experience art in an active, kinesthetic manner. These experiences can exemplify, probe, or question how humans think about objects, each other, and themselves. This paper presents work using installations to explore human perceptions of robot and human capabilities. The paper documents an installation, developed over several months and activated at distinct venues, where user studies were conducted in parallel to a robotic art installation. A set of best practices for successful collection of data over the course of these trials is developed. Results of the studies are presented, giving insight into human opinions of a variety of natural and artificial systems. In particular, after experiencing the art installation, participants were more likely to attribute action of distinct system elements to non-human entities. Post treatment survey responses revealed a direct relationship between predicted difficulty and perceived success. Qualitative responses give insight into viewers' experiences watching human performers alongside technologies. This work lays a framework for measuring human perceptions of humanoid systems - and factors that influence the perception of whether a natural or artificial agent is controlling a given movement behavior - inside robotic art installations.
\end{abstract}

Keywords: human robot interaction, robot performance, embodied learning, virtual reality

\footnotetext{
${ }^{\star}$ Corresponding Author: Catie Cuan: Department of Mechanical Science and Engineering, University of Illinois at UrbanaChampaign, Urbana, IL, USA; Independent artist, New York, NY, USA; Department of Mechanical Engineering, Stanford University, Stanford, CA, USA; E-mail: ccuan@stanford.edu

Erin Berl, Amy LaViers: Department of Mechanical Science and Engineering, University of Illinois at Urbana-Champaign, Urbana, IL, USA
}

\section{Introduction}

Vice Versa: A Lesson to Fathers, written by Thomas Anstey Guthrie under the pseudonym F. Anstey, was published in 1882 [1]. The novel marks a first and highly influential appearance of a new literary and cinematic device: the body swap [2]. In it, a father and son use a magical stone to switch bodies for a series of days, and thus gain an empathetic understanding of each other's plights. When returned to their own corpus, each relishes the familiarity of their existence but cannot forget the transformative experience of occupying another body.

They say to know a man you must "walk a 1000 miles in his shoes". This colloquialism captures an idea that is deeply rooted in humanity: to know a person is to occupy their physical being. And this extends to our environment: to know a thing is to move through the world with it. When we see a new, unfamiliar object, we pick it up, turn it over in our hands. Robots, and experiences moving with them, are a rarefied set of devices limited, for the most part, to factory and laboratory settings. How, then, will the broad public get to know robots as these devices move into homes? In this paper, we focus on the roles that roboticists and artists can play in answering this question. We are interested in how the two groups, when working together, can uniquely pose and probe questions about our future with robots.

Recent reports from the International Federation of Robotics found that the number of worldwide in-home and industrial robots is rising across the world [3]. However, the number of these devices is still relatively low when compared to other technologies like televisions or smartphones $[4,5]$. Thus, the context in which a robot is met and one's prior experiences with robots may not be in their personal life, but instead through witnessed stories, in media and the arts, about robots. In order to measure how robots are perceived by the general public, researchers have generated new metrics to study human-robot interaction [6,7].

Prior work showed that humans treat computers and other technologies with human-level sensibility, while 
simultaneously recognizing that these technologies are not human $[8,9]$. Further experiments in this area have demonstrated that humans apply these same expectations to robots $[10,11]$. Factors that influence individuals' perceptions of robots include the design of the robot, the context in which the robot is met, one's cultural background/beliefs/life experiences, and one's prior experiences with robots. [12-17]. Groups of humans attribute socialness and animacy to robots as well $[18,19]$.

One measure of understanding individuals' perceptions of robots is through the lens of expressivity. The term "expressivity" can be associated with traits that are expressed via one's genetic code or the notion of being more or less expressive. One appropriate definition for this paper is "effectively conveying meaning or feeling through exhibited behavior". Roboticists have explicitly designed robots to account for the expressivity of the system [20] [21]. Strategies for programming existing robots with expressivity values appear in [22, 23].

Current Western perceptions of robots skew negative. $72 \%$ of Americans are worried or very worried about a future where robots can do many human jobs [24]. More Americans are afraid of robots than they are of death [25]. In parallel, we don't have a good way to talk about the action of autonomous artifacts deposited by robot designers [26]. Interdisciplinary art and research is a setting to grapple with these questions.

Roboticists and artists have often generated collaborative performance and research projects. Goldberg's multiple artistic efforts fuse dance, sculpture, teleoperation, robotics, and mixed media visual art $[27,28]$. Burton and Kulic used Laban Movement Analysis (LMA) to create bio-inspired active sculptures for art installations [29]. Gemeinboeck and Saunders examined relationships between robotic art, performance studies, and computational creativity [30].

Prior work examined challenges in expressing narrative-inducing motion on nonlinear systems via a collaboration between roboticists and puppeteers [31]. Puppetry theater has been a medium for studying robots and developing control systems to execute the timing needed to drive puppet narratives [32]. Dancers have controlled robots' movements [33]. Dancers' movement expertise has been employed to socialize and create relationships between non-anthropromorphic robots [34]. A performance alongside professional dancers with the Softbank NAO robot conducted exploration of style on moving bodies [35]. Placing an experiment in a performance setting has been explored in $[36,37]$, concluding that artists should be involved in all stages of the robot programming process and that qualitative and quantitative data is essential to capture the participants' experiences.

Classic experiments in human motion occluded the human form, leaving only the motion of a handful of selected spatial points on the body (an early precursor to motion capture) [38]. These experiments have shown how accurate humans are at recognizing motion generated by human bodies even with only partial information about the original activity [39]. Extensions to this work have added to neural models of motor behavior [40, 41]. Moreover, Turing Tests for robots - where the challenge of creating artificial motion that passes as human motion is posed - have been proposed, and at least partially, passed in certain limited contexts [42]. In parallel, technology for generating and recording creative movement has also been explored. Cunningham used technology throughout his career [43, 44]. Others have worked to create tools for choreographers to generate new movement [45-47], and additional work studied translations between actors and robots in [48].

The mirror game is an activity frequently used in dance, movement therapy, and improvisational theater. There is a loose structure, with an initial description that two individuals will begin moving together and attempt to replicate the movement of the other person, without a clear leader or follower. This task results in two individuals moving in roughly the same way while facing one another. Experimental studies have shown that individuals can synchronize movement quickly and remain synchronous within a close range more successfully during the mirror game than when a clear leader is designated. [49]. Additional study of the kinematics of individuals participating in the mirror game has been used towards the aim of generating human-like motion for virtual reality characters [50]. Experimental data of individuals playing the mirror game populated a theoretical model which then drove a virtual reality avatar in [51]. We use this frame to drive the action in the installation discussed in this paper. Based on comments from participants in prior venues, we also want to know how people rate their own performance in these experiences.

Perceptions of self are generated by life experience and one's prior and current perceptions of external forces and agents. Self-perception and self-esteem can be influenced by many factors, including gender [52], choice of major [53], age group [54], quality of job [55], race [56], and body image [57]. Individuals perceive new tasks often through the lenses of difficulty and success.

Movement has been integrated into pedagogical methods through the field of study known as embodied learning $[58,59]$. Novel technologies like mixed reality have been employed in educational contexts in addition to art instal- 
lations. The combination of embodied learning with immersive technologies is summarized in [60].

\subsection{Paper outline}

Our prior work embedded an experiment in a performance and an art installation setting to examine perceptions of control in technological systems as well as the perceived expressivity of various anthropomorphic and nonanthropomorphic agents [61-63]. This paper extends this work, focusing on extending the art installation described in [63] to a new venue with a larger participant pool and more thorough participant experience (both prior to and during the installation) measures.

This section has outlined background of embodied learning, robots in work and home contexts, robots and unusual technology in artistic collaborations, and the research team's prior work at these junctures. The paper will next describe the research motivations and artistic themes in Section 2. The paper will then recount earlier iterations of the experiment structure and additive learnings from each event in Section 3. The final experimental set up is described in Section 4. After this, the relevant results from the most recent version will be examined in Section 5. Final discussions and conclusions will be offered in Section 6.

\section{Towards shared artistic motivations and research questions}

The performance piece and installation, entitled Time to Compile and credited as a collaboration between an artistin-residence and the research group, "Catie Cuan x RAD Lab", ventured within the space of the following themes, which are visualized in Figure 1:

- The transference of human-like or robot-like qualities between humans and robots. The unconscious or conscious manner in which these qualities may be transferred, embraced, or rejected, and the modes in which they manifest across interface, society, and selfconception.

- The proliferation of human choice and action in every seemingly autonomous artifact. A metafictional narrative of human creators inherent to every artificial construct.
- The spectrum of compile times for generating and performing human movement versus generating and performing machine or artificial actuator movement. In the latter case, for example, conversion from level coding languages to machine code may result in errors and frustratingly extended compile times. This phenomenon is rare inside human choreographic processes.

The overall title references this final theme. As later iterations began to include audience participation during both the performance and the installation, the compile time extends to audiences as well, meaning the exploratory span over which an audience may experience a performance and then perhaps alter their beliefs as a result. The credit of the piece refers to the mutual research and artistic process present throughout the working and performance period. It also refers to the critical and equal contributions of all collaborators, and the spatial grounding of the physical laboratory environment where nuclei of the work were conceived and cultivated.

The installation was inspired by the artists' personal re-calibration of assumptions about unfamiliar technology after spending several weeks in residence in a robotics lab. The artist aimed to cultivate a similar transformation for audience members, allowing the audiences to experience moments of surprise and a retelling of stories about robots and themselves. In order to bring the audience into a similar space of assumption questioning, the embodied installation was comprised of interactions the artist engaged in with the various robots and sensor technologies in order to become familiar with their movement possibilities.

The installation was also inspired by Turing Tests, and the notion of engaging audiences in a movement-based Turing Test, rather than a written or verbal one. Thus, the mechanisms controlling each non-human agent in the installation were obfuscated from the participants. After completing the mirror game interaction with each agent, the team asked the participants to identify this control mechanism. Thus, by asking participants the source of the movement they were mirroring, the work was an embodied form of Turing Test.

The installation was thus an abstract, movementbased experience with robots that was non-competitive, meditative, and revealed the full technical implementation at the end ("raising the curtain" on the technology involved). Over several public activations of the artistic installation, however, the collaborative team noticed people's fear of failure and concern for their performance, 

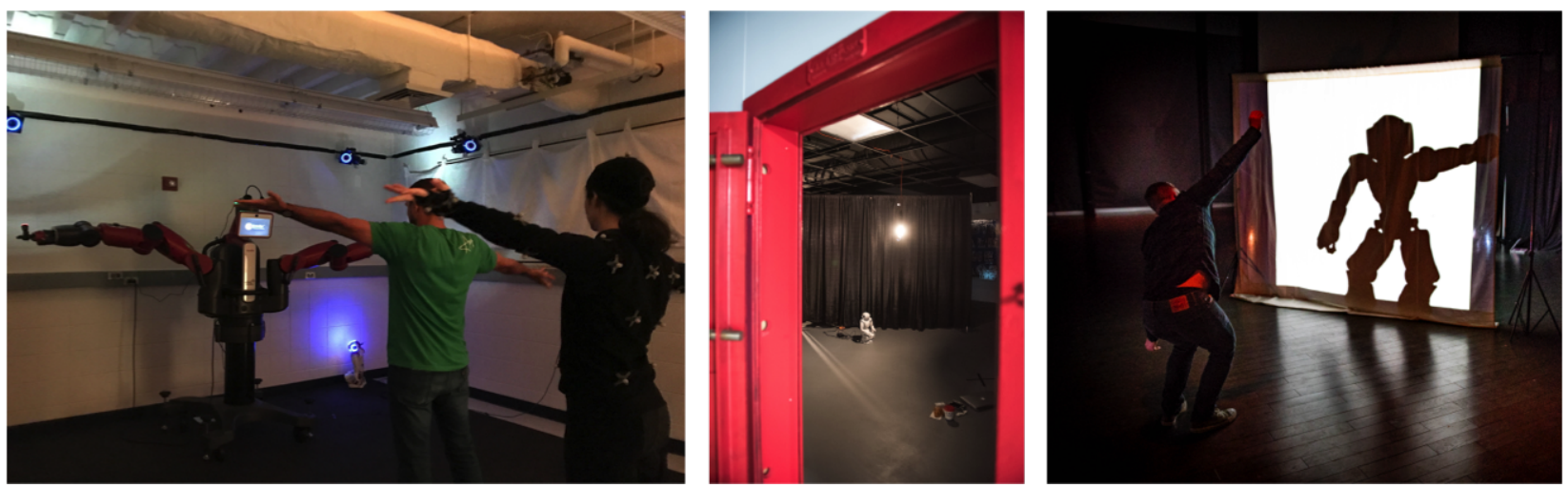

Figure 1: Images showing the themes of the Time to Compile installation. On the left during an early instantiation of the installation: a participant in a green shirt follows the movement of the Baxter, unaware that they are being followed by a human performer in a motion capture suit behind them, illuminating the theme of human involvement inside technology and robot-like interpretations. In the center: a NAO robot while booting, viewed through the portal of a red door, showing the voyeurism of ubiquitous cameras as well as machine compile times. On the right: a large projection screen broadcasts a scaled-up shadow of the NAO robot, illuminating the hidden network nature of many technologies.

rather than a trend towards empowerment, epiphany, and revelation.

Thus, the work described herein endeavored to understand individual's perceptions of control in robotic systems and the anticipated difficulty of navigating movement exercises with them. Individuals lacking experiences with robotic or virtual reality technology may have been exposed to them through fiction, and thus an artistic installation setting was employed to cultivate a dynamic, imaginative setting. Further, we predicted that humans will perceive technological forms to be controlled by algorithms and, in addition, that individuals with several years of movement experience and positive attitudes towards that experience will be less anxious about the prospect of moving with a variety of humanoid forms.

The elements of the installation varied over instantiations, as outlined in detail over Section 3. The systems in the installation included but did not fully overlap with the systems in the performance [61, 62]. The design elements of the performance and installation included dance, text, video, robotics, virtual reality, light manipulation, music, live streaming, set design, and internet links. Throughout, the artistic and research goals grew increasingly synergistic. This is due to the overlapping aims of artwork: to imagine and build an experience for the audience, and the aims of research: to measure experiences and changes in human subjects. Thus, research questions began to emerge:

1. Can movement based tasks change people's perception of unfamiliar objects?

2. Where do people perceive power/agency in moving human-like things?
3. How do individuals with differing movement and technology backgrounds anticipate a movement experience with an unfamiliar technology?

\section{Evolving data collection structure}

A variation of the Contextual Understanding of Robot to Audience INteraction (CURTAIN) framework, described in [62], was employed. In the CURTAIN framework, an audience of research participants views a performance including robots and other novel technologies prior to interacting with them. In this paper, the experiments were limited to the interactive component of Time to Compile only, previously described in $[61,63,64]$. The aim of the interactive installation was to comprehend how audiences' perceptions of the installation agents would affect their selfevaluation of the task and/or vary based on their background.

The overall structure of these experiments is shown in Figure 2. The experimental structure is delineated below.

1. The audience fills out a pre-survey which includes questions about their perceptions of various robotic and human agents.

2. The audience travels through a participatory, embodied art installation in incremental stations with timed intervals.

3. The audience completes a post-survey, inquiring about their perceived control of systems in and out of the installation, as well as their movement and technological background. 


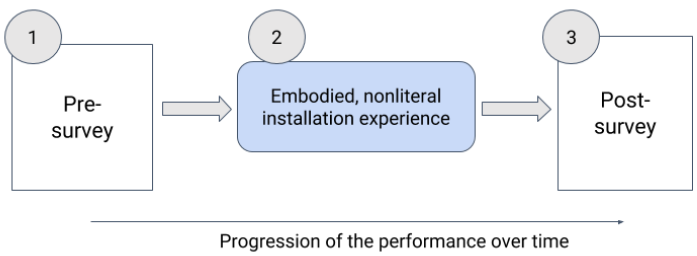

Figure 2: The experiment design illustrated from beginning to end. Two surveys were used to collect initial audience perceptions followed by their perceptions post participation in the installation. The surveys were completed in a separate, smaller area tangential to the installation, therefore delineating visual and environmental differences between the installation and the research collection spheres.

This paper reports on four instantiations of this experiment, including the execution outlined in [62]. At each instantiation, refinements to the experimental setup were made in order to facilitate:

1. Portability of the setup to different cities and public spaces

2. Continuity in the experience from participant to participant

3. Efficiency and consistency in the experiment timing to allow for increased participant numbers

4. Robust understanding of audience's backgrounds with technology and movement

In some executions, the performance and interactive installation were coupled. Audience members conveyed frustration with the online survey sections in terms of connectivity logistics, performative continuity, and task completion time. Later instantiations attempted to remedy these audience concerns, particularly by isolating the installation completely from the live performance. The experimental protocol therefore needed to balance artistic intentions, research aims, and feasibility. The resulting modifications and their causes are outlined here.

\section{Performance 1: The Robotics, Automation, and Dance (RAD) Lab at the University of Illinois at Urbana-Champaign, IL, June 30, 2017}

A workshop version of the artistic installation occurred after a four week residency period of incubation at the RAD Lab. In this showing, each element of the residency was first discussed out loud and then shown in sections. A short live performance occurred in the laboratory space and then the group of roughly 16 audience members exited the room while the installation was activated. Audience members entered the room one by one to participate in the installation, which included the following interactive stations: first, an iPad equipped with a drawing application and a stylus, second, an HTC VIVE virtual reality headset, and third, a Baxter robot (with a performing dancer in an OptiTrack motion capture system following the participant at the Baxter station). No experimental data was captured at this iteration. A prerecorded musical interval played in order to signal when to start moving in the installation.

\section{Performance 2: The Robotics, Automation, and Dance (RAD) Lab at the University of Illinois at Urbana-Champaign, IL, December 16, 2017}

The installation was again preceded by a short performance as well as an artistic film. The installation included different interactive stations: first, a projected video of a large, shadow robot, and second, an HTC VIVE virtual reality headset. In order to showcase the cyclical, mirroring nature of the installation, an additional, non-interactive station was introduced. The station included a live stream of a 360 camera placed roughly 7 feet high in the center of the lab room, so participants could watch a video of themselves participating in the installation. This allowed them to recognize the shared movement across several participants simultaneously. Roughly 15 audience members participated in this instantiation and no experimental data was collected.

\section{Performance 3: The Granoff Center for the Performing} Arts, Brown University, Providence, RI, March 9, 2018 This instantiation was at a closed academic conference. The artistic installation was preceded by an extended performance at this instantiation. This was the first event when research data was formally collected. Several ushers were situated around the installation to guide participants through. Three surveys were situated in the performance: at the beginning of the performance, at the intermission between the performance and the installation, and at the end of the installation. The formalization of this experiment is discussed in detail in [62]. A total of 17 audience members were research participants. The installation included the following interactive stations: first, a NAO robot with a projector behind it to create a massive robot shadow, second, an HTC VIVE virtual reality headset, third, a Baxter robot with flashlights on the end effectors, and fourth, a human performer. The audience members who did not participate in the installation could watch from a floor to ceiling glass viewing floor elevated above the installation area. This "reveal" for the viewers, like the 360 camera, was aimed to close the circle of understanding about one's 
role as both participant and instigator in technological networks and society writ large. Logistical constraints at later performances halted the "reveal" practice from Performance 2 and 3.

\section{Performance 4: Casa Paganini, Genoa, Italy, June 29, 2018}

This instantiation was also at a closed academic conference. The installation was separated into a standalone event. Surveys were completed on a single computer that was reset by a research assistant in order to ease data collection. The sound cues to begin moving in the installation were manually controlled to allow for any errors in the switching process. The following interactive stations were included: first, a NAO robot, second, a projected video of a NAO robot, third, an HTC VIVE virtual reality headset, fourth, a human performer, and a final auxiliary station to draw your experience inside the installation. Questions were also included in the final survey asking participants what they believed was motivating the movement of the agents inside the piece. 22 audience members were research participants at this event. Analysis of the data collected in this performance is described in [63].

\section{Performance 5: MINDSET Brain Gym, Toronto, Canada, October 21, 2018}

Survey questions were expanded to include topics like prior background with movement and technology. After reviewing Performance 4 results, it was apparent that participants were using the lens of difficulty to assess their performance in the installation. Survey questions were added to parse this more fully. The experiment was open to and advertised for the public. The following interactive stations were included: first, a projected video of a NAO robot, second, a NAO robot, third, an on-screen avatar, and fourth, a human performer. The music was again manually controlled to allow for variable timings of participant arrival. The survey questions were printed.

\section{Experimental setup}

The remainder of this paper discusses the setup in Performance 5 and analysis of the subsequent data collection. This section gives detail on the set up at this execution as well as the data collection process. The venue that hosted this execution was a "meditation gym" in Toronto, Canada, where the installation ran all day during their business hours and attracted some of their regular clientele as well as others who saw advertisement for the event.

\subsection{Final technical implementation (Performance 5)}

The installation is a series of stations, also referred to as "nodes", where a participant is asked to follow the movement of a specific agent in front of them. The agent is also referred to as an "actuator" or "moving stimulus". The participant follows each agent for a pre-allotted time, signaled by the starting and ending of a musical track, before moving on to the next station and agent.

Unbeknownst to each participant, there is a sensor at each station that is driving the movement of the agent at a station nearby. In doing so, the participant is both a follower of the agent and the leader of a different agent and therefore the leader of a different participant. The installation is thus a large game of movement "telephone," supplemented by deception and aesthetics.

The final technical implementation (Performance 5 from the previous section) is shown in Figure 4. It is comprised of four nodes and takes approximately 10 minutes to experience. Each node has a large black ' $X$ ' taped to the floor where the participant is meant to stand.

In Node 1 (upper right quadrant of the images in Figure 3 and upper right quadrant of the schematic in Figure 4), the participant (Participant 1 ) is asked to follow the movement of a giant two-dimensional shadow of a NAO robot. The projection screen is 8 feet tall and 8 feet wide. The shadow is generated by a projector connected to a laptop that is running a video recording of the robot. The video is a recording that does not change. At Node 1, an iPhone is placed roughly 15 feet behind the moving participant. The iPhone is connected to Skype and engaged in a call with another iPhone on the other side of the installation. Therefore, Participant 1 is unaware that their movement is captured and streamed to another section of the installation.

In Node 2 (upper left quadrant of the images in Figure 3 and upper left quadrant of the schematic in Figure 4), the participant (Participant 2) is asked to follow the movement of a 1'11" high NAO robot. This station swaps dimension and scale from the first station, presenting the "real" NAO, at its true height and physicality. The NAO is being controlled over Wi-fi by a laptop running Choregraphe using the Naoqi SDK. The NAO's movement is a preset sequence that does not change. There is no sensor at this station.

In Node 3 (lower left quadrant of the images in Figure 3 and lower left quadrant of the schematic in Figure 4), the 


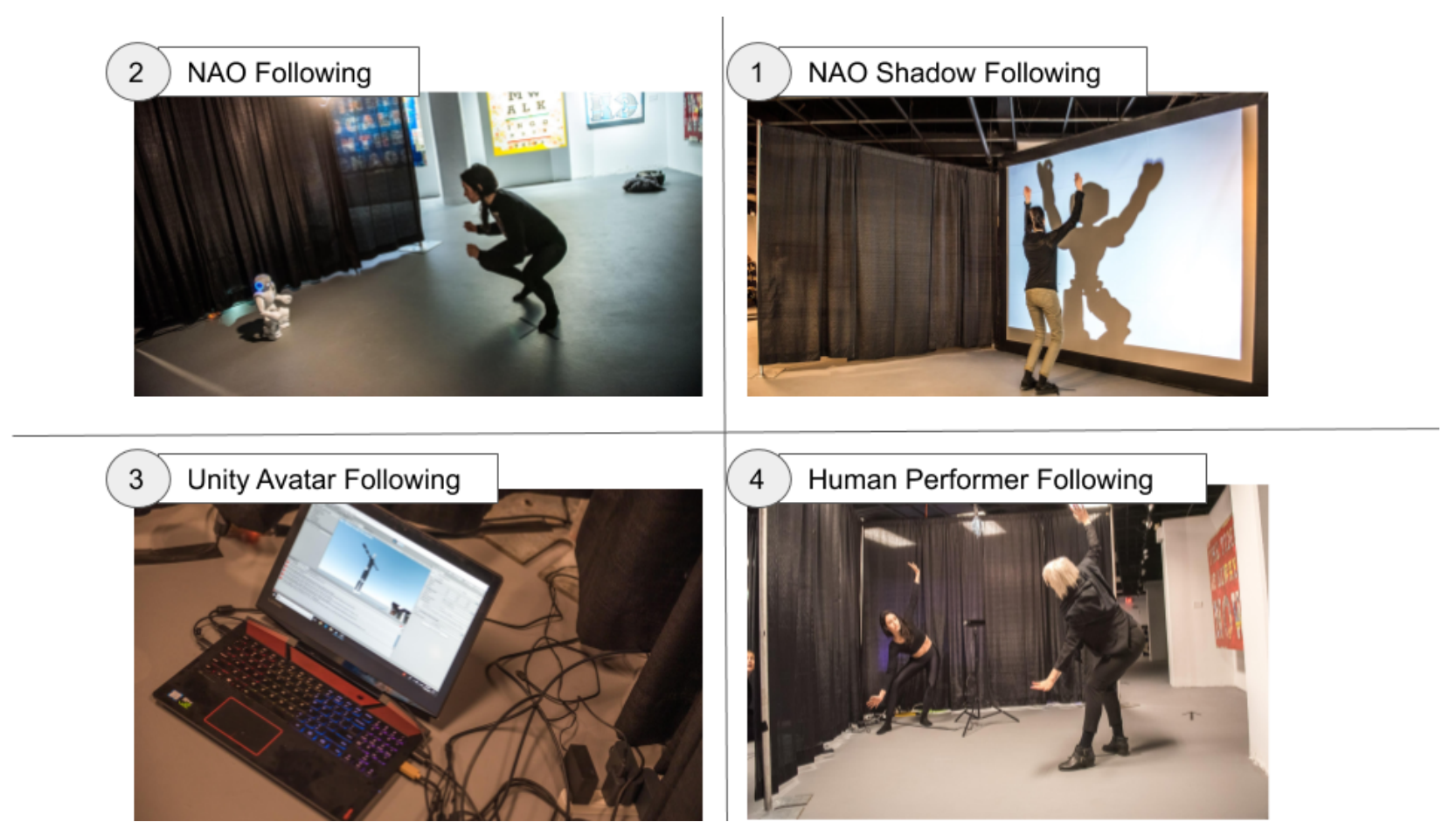

Figure 3: Images from the interactive installation at Mindset Brain Gym in Toronto, Canada. The participant began by following the large shadow of a NAO robot in the first node, then a real NAO robot in the second node, then an avatar of a human as translated by the Unity software in the third, and finally a human performer in the final fourth node. A schematic of the four stations at the final Performance 5 event is shown in Figure 4.

participant (Participant 3) is asked to put on an HTC VIVE headset and follow the movement of a black and white humanoid avatar in virtual reality. The headset is connected to a Windows workstation that is running Unity 3D, a virtual reality experience software. The avatar is driven by skeleton tracking information from a Microsoft Kinect v2 sensor facing Participant 4 in Node 4. There is no sensor at this station apart from those in the VR headset, which tracks the wearer's movement and factors this in to the rendering of the avatar motion.

In Node 4 (lower right quadrant of the images in Figure 3 and lower right quadrant of the schematic in Figure 4), the participant (Participant 4) is asked to follow the movement of a human performer. The human has been trained in dance and theater, with extensive experience in improvisation. There is an iPhone facing the human performer and a Kinect v2 sensor facing Participant 4 situated in between the human performer and Participant 4's standing location. The human performer is viewing the Skype call from Node 1 showing Participant 1 following the shadow. The human performer interprets Participant 1's movement and moves continuously while Participant 4 follows. The Kinect is connected to the Windows workstation and sends Participant 4's movement to the avatar.
Heavy theatrical curtains were used to construct the walls separating each node. They are flush to one another and meet in an ' $\mathrm{X}$ ' or ' $\mathrm{T}$ ' shape, creating triangles for each Node.

\subsection{Final experiment design (Performance 5)}

The final experiment structure, at Performance 5, is detailed below:

1. An audience arrives at the installation location and completes a pre-survey inquiring about their anticipations of the installation and their perceptions of various familiar and unfamiliar technologies and items.

2. The audience members engage in a timed, solo embodied installation with different moving agents. They follow the movement of each agent before venturing to the next station, cued by music and ushers.

3. The audience completes a final survey, inquiring about their experience inside the installation and their personal background with particular focus on the roles technology and movement play in their lives.

Prior to entering the installation area, audience members completed the pre-survey in a holding region separate 

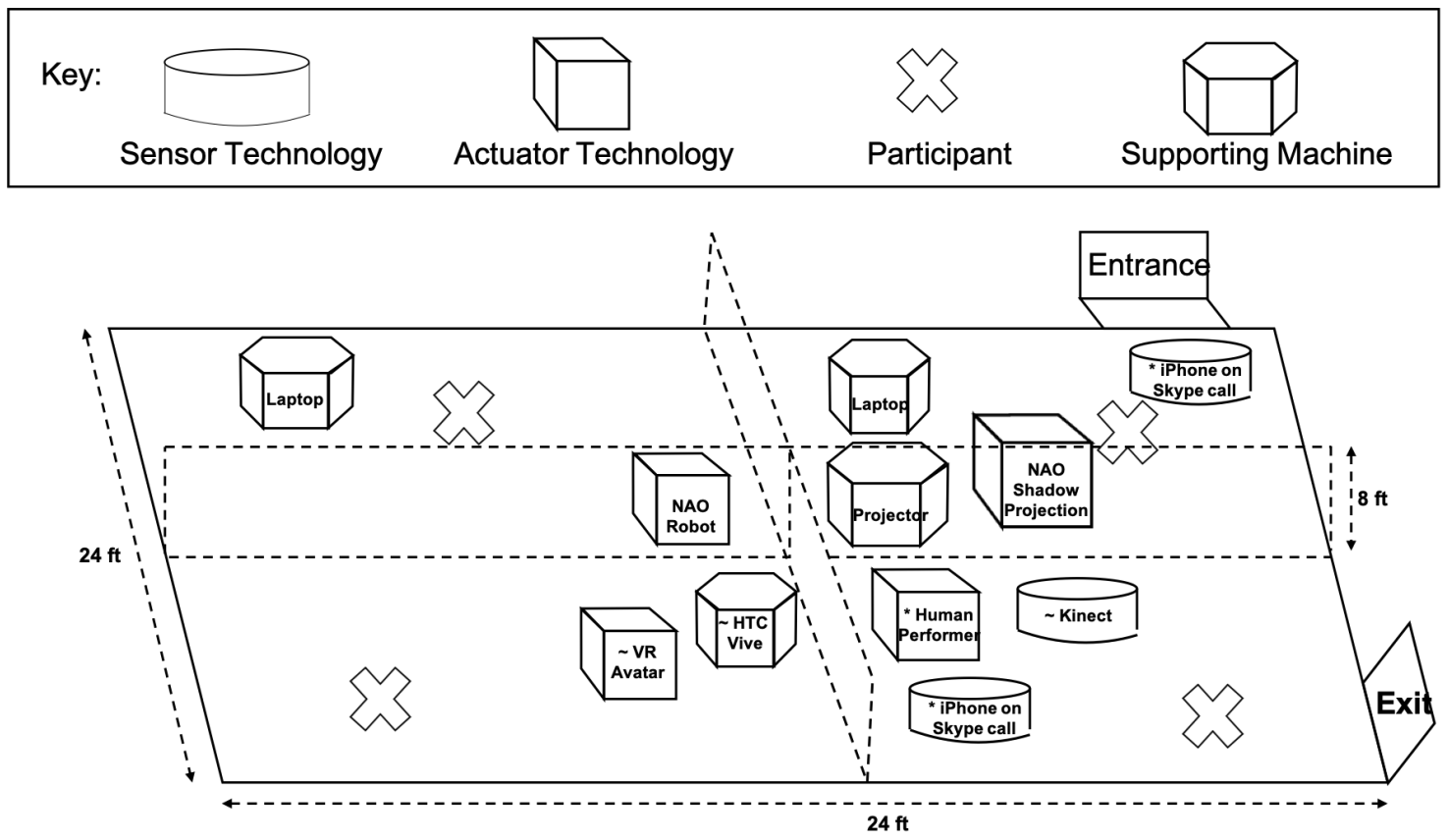

Figure 4: The various nodes of the installation experience. Elements that are connected during the installation or that are interacting with each other are indicated here through the same symbol beforehand (for example, HTC Vive, VR Avatar, and Kinect all preceded by a tilde). Participants moved in a counterclockwise direction through the four quadrants, from entrance to exit, with their general position in the space indicated by an $\mathrm{X}$ in each quadrant.

from the installation. This was purposely out of view so as to maintain the suspense of the installation and the fidelity of the research data. A researcher then invited participants into the installation area one at a time in order to begin the first following exercise. The researcher explained to the participant that they would be mirroring the movement of different agents and that sometimes the task would be easy and other times impossible. The participant was instructed to make choices about the way they followed each agent. The researcher also noted that the participant should begin moving when they hear music, and move on to the next station when they no longer heard music. The participant stood on a black ' $\mathrm{X}$ ' taped on the floor in order to maintain consistent reading positioning for the sensor technologies at each station. The participant removed any purses or thick coats at the start of entering the installation.

The agents in the installation varied in size, dimension, and movement patterning, among other differences. The participant stood across from a single moving agent at a time. No other observers watched them move except for ushers. The other aspects of the installation were hidden from view by black drapes and low lighting. At each station, participants were again instructed to follow the movement of the agent in front of them. If the participant questioned the task, ushers noted there was no right or wrong way to engage with the installation, reminding the participant to follow the agent as they saw fit. This instruction is necessary both due to the morphological differences between the participant and the various agents in the installation and in order to ensure that the installation was accessible to participants of many movement backgrounds, modalities, and abilities.

The pre-survey was composed of four sections:

1. Definitions. Write definitions for the words, "roboticist", "choreographer", and "future".

2. Pairings. Five pairs of various humans, robots, and items were placed side by side and the participant chose which in the pair was more normal, expressive, positive, and powerful. The items in those pairings are included below.

3. Motivation and Performance. This section was preempted with the text: "You are about to enter a series of mirroring tasks. You will be asked to imitate the motion of another system with your own body. Please answer the following questions that relate to these tasks, described in the pictures below." Four photos, one of each agent in the installation, were then included with the questions asking the audience members to select what they believed was motivating the movement of the system, the anticipated difficulty of the task, and their anticipated success in the task.

4. Emotion. Participants were asked to select emotions that described how they felt about the installation 
task. Their choices where: nervous, anxious, apathetic, indifferent, excited, thrilled, curious, calm. The purpose of this exercise was to bring participants into an awareness of their body and their feelings; we do not anticipate, especially for this small sample size, that the results of this will have a significant pattern.

The post-survey was composed of five sections:

1. General experience. Participants were asked to draw their experience in the installation, write sentences about it, and name it.

2. Motivation and Performance. The same section as in the pre-survey, and now including the drawing task as a fifth station.

3. Definitions. The same as the pre-survey.

4. Pairings. The same as the pre-survey.

5. Background and Demographics. This section asked about the participant's device usage, application usage, and technology skills (ranging from "Join a Wi-Fi network" to "Program a robot", for example) as well as their movement practices (ranging from "A single yoga class" to "Dance in performances”, for example). It also included general demographics questions.

The items included within the pairing sections of the preand post-surveys were the following:

1. A wooden abacus

2. A female professional performer

3. A NAO robot

4. A wooden human hand

5. A male volunteer

6. An iPhone

7. A wooden turntable

8. A t-shirt

9. A MacBook Pro laptop

Participants had varying exposures to artistic installations and/or embodied experiences. Some participants attempted to take pictures and others asked several questions about the agents at the stations before beginning to move. Contrasting this, some participants journeyed through the installation without questions or pauses. The surveys were both printed in color and collected on site.

All participants observed and completed the mirroring task with the same four agents in the following order: Shadow NAO, NAO, Virtual Reality Avatar, and Human Performer. Some of the new questions asked in Performance 5 examined predicted difficulty and success compared to later perceived difficulty and success at the task. New questions investigated motivation of the movement that participants observed, and further questions investigated move- ment and technology background, including literacy and valence.

\section{Results and discussion}

This section considers the results from this new examination through Performance 5, with $\mathrm{N}=18$ (the demographic information on this performance is given in the Appendix). The participant pool contained an even gender split, the majority were English-speaking Canadians in the age range of 35-44 with Bachelor's degrees, from urban areas.

\subsection{Perception of movement motivation}

Participants were asked before and after the experience what they thought was motivating the movement of each system. They were given the options of Human Actor, Automated Algorithm, Yourself (meaning the participant), Another Participant, or Unsure. The data from these questions can be found in Figure 5. Overall, participants were less likely to cite human design (either Human Actor, Yourself, or Another Participant) in the motivation of each moving element after experiencing the installation.

While the perceived motivating movement source of the Shadow NAO and the NAO did not show much variation, there was a decrease from before to after the performance in those who answered Human Actor as the movement motivation for the Human Performer. An even larger decrease appeared from before to after the performance for the answer Human Actor for the Virtual Reality Avatar. This is a notable result because the movement of the Avatar was actually motivated directly by a Human Performer, as another participant moved in front of a Kinect sensor in a later station.

\subsection{Ratings of descriptive words examined through pairings}

This examination of the data combines two larger sections of the questions asked, bringing together the Literacy and Valence data with the self-evaluation data about Difficulty and Success. After the experience, participants were asked extensive questions on their technology (devices, applications, and skills) use and their movement practice background. They were also asked with each question how they felt about that technology use or movement practice. For 

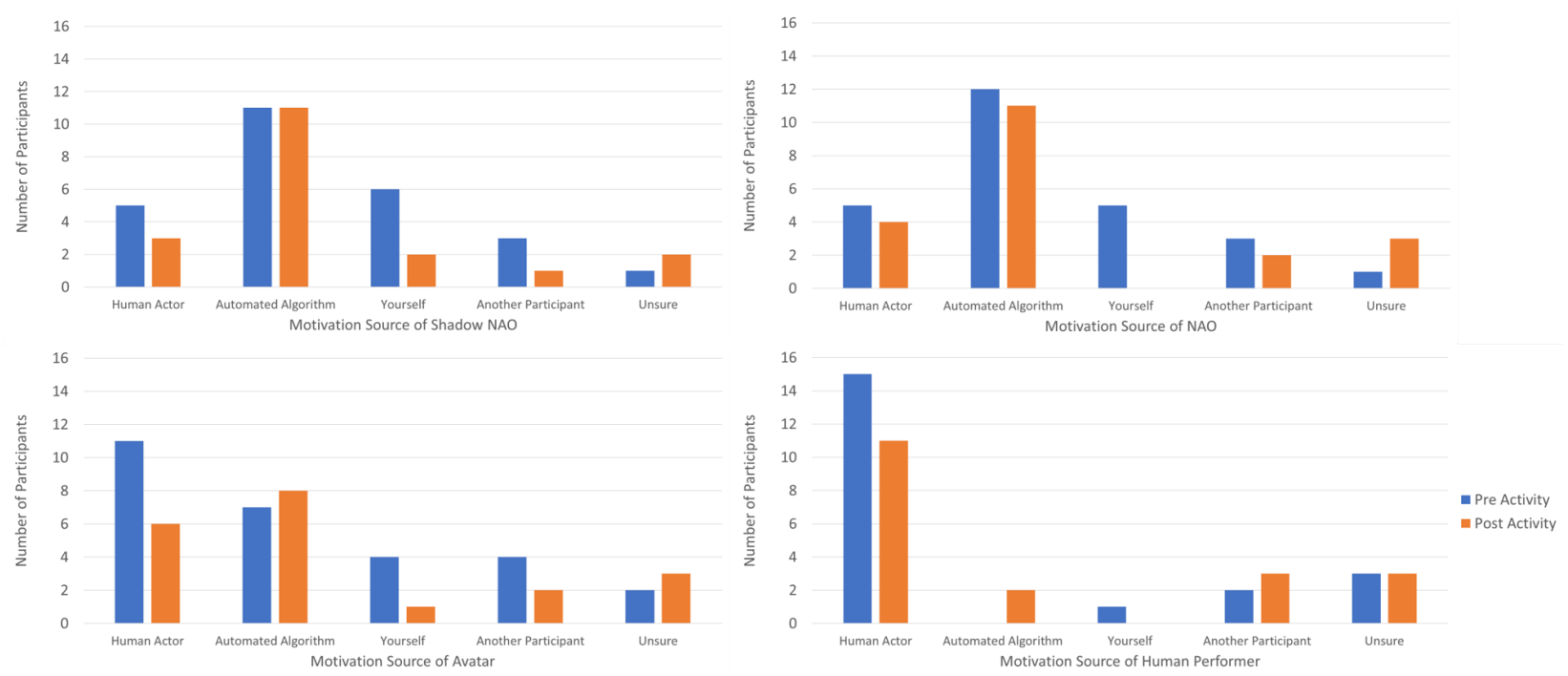

Figure 5: The perceived motivating source of each item in the installation rated by all Performance 5 participants. The two bottom charts, showing “Avatar Movement Motivation" and "Human Performer Movement Motivation," show decreases in the Human Actor as motivation source from before to after the performance. This is notable as the Avatar was being driven directly by Another Participant in front of the Kinect sensor in the neighboring station.

example, they would answer how often they used their phone (hourly, daily, weekly, monthly) and how positive or negative they felt about that use of their phone (love and can't live without it, like but don't feel like I need the functionality, hate and wish I didn't have to use it, or dislike but feel I need the functionality). These answers were then given corresponding point values, and these were all compiled into four metrics for each participant: Technology Literacy (TL), Technology Valence (TV), Movement Literacy (ML), and Movement Valence (MV). The before and after experience pairings questions were examined in these contexts, grouping participants into Low, Mid, or High for these four metrics.

Figure 6 shows how participants across the different levels of these four metrics (TL, TV, ML, and MV) answered questions comparing the normalcy, expressivity, valence, and power between a picture of a male performer versus a cell phone. This pairing of Male and Phone is intriguing to examine in the context of this performance specifically, as neither a Male performer or a Phone were included in the performance, but each is a common representative of humans (natural systems) and technology (artificial systems). For this pairing, the question of which system was more positive showed the smallest variation. All participants, regardless of TL, TV, ML, or MV, answered that Male was more positive than the phone both before and after the performance.

The question of which system was more normal was found to be connected to both TL and TV. If people use technology often, they most likely have a higher resulting TL score and may be more likely to view technology as more normal than those with a low TL score. The same may be a legitimate predictor for a higher score on the question of which is more normal for the TV metric.

This speculation is supported by the data from Performance 5. Those with a low level of literacy with technology (Low-TL) all answered Male was the more normal system both before and after the performance, preferring the human component of the pairing rather than the technology component. A lower number of Mid-TL participants answered Male as the more normal system, and the lowest number of High-TL participants answered Male as the more normal system. The same inverse relationship was found for the TV metric as well. Those with Low-TV all answered Male as more normal, while a lower number of MidTV participants and the lowest number of High-TV participants answered Male as more normal.

The largest amount of variation was found in the question of which system was more powerful. A notable change from before the performance to after was found in the High-TL participants. While all High-TL participants chose Phone as more powerful before the performance, half of the High-TL participants chose Male as more powerful after the performance. This difference can be seen in the top left chart of Figure 6. While this was the largest difference seen in the pairings, the High-TV, High-ML, and High-MV participants all also showed increases in the answer of Male as more powerful after the performance. 


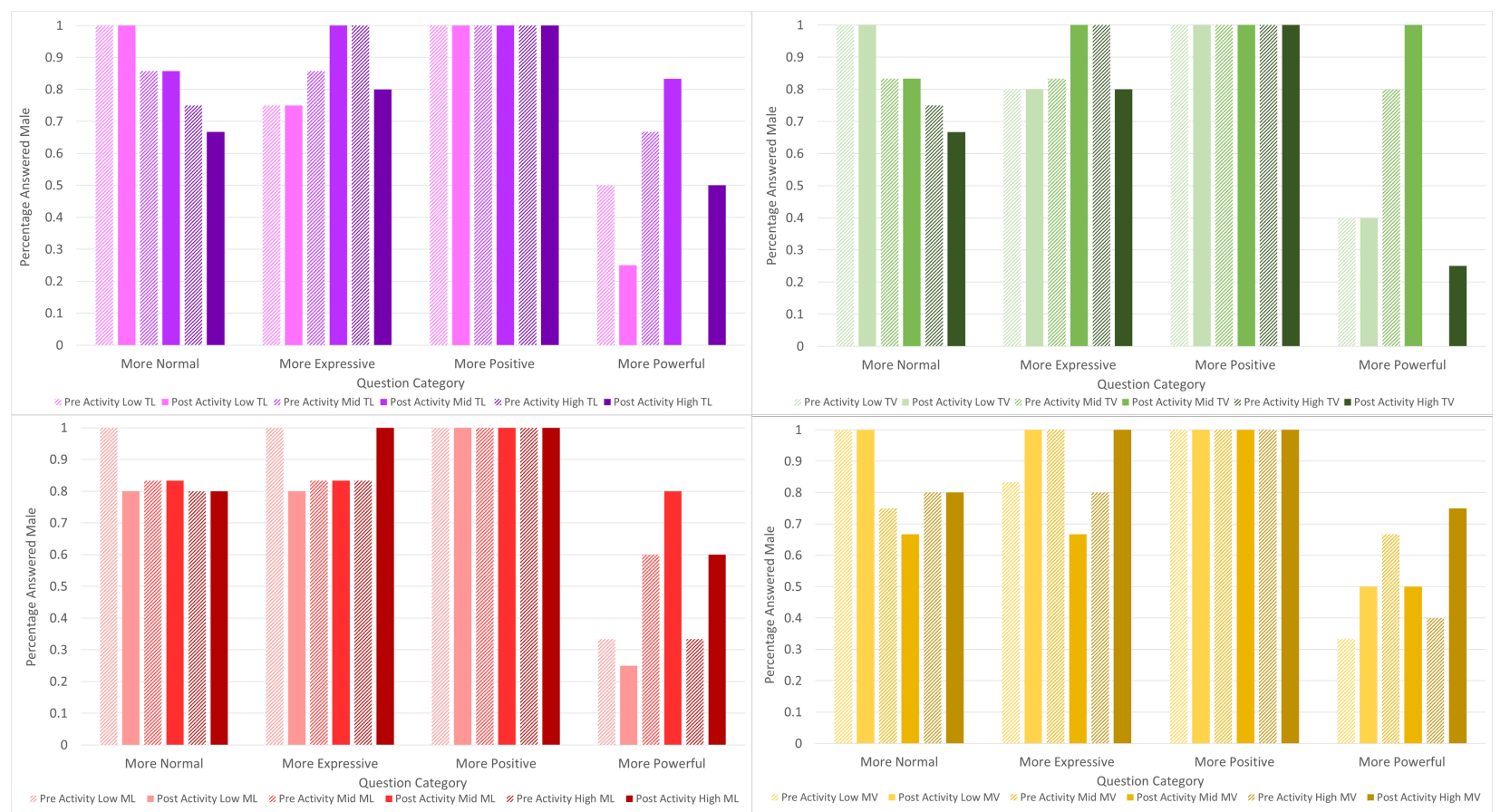

Figure 6: All pairings of Male vs. Phone, showing how many participants rated Male as more normal, more expressive, more positive, and more powerful. These are separated into three levels (Low, Mid, High) of four metrics (Technology Literacy, Technology Valence, Movement Literacy, and Movement Valence). All participants, regardless of level of metric, reported Male as more positive.Low-TL participants rated Male as more normal both before and after the performance. The lowest number of High-TL participants rated Male as more normal. While all High-TL participants chose Phone as more powerful before, half of the High-TL participants chose Male as more powerful afterwards (all High levels of the four metrics show increases in the answer of Male as more powerful afterwards).

Another noteworthy pairing to examine is Abacus vs. Female Performer, which is shown in Figure 7. The Female Performer was in the installation (as the fourth agent), and the abacus is an antique piece of technology that is not digitally controlled. Some of the changes from before the performance to after were more significant than others, but all participants rated the Female Performer as more expressive after the performance. While more research is needed to properly quantify and examine this difference, this observation may help support the idea that people that appear in performances are rated as more expressive, as the same ratings were not found in the Male vs. Phone pairing for that example of a human on the question of expressivity, as shown in more expressive sections of Figure 6. The largest changes from before to after the performance for the question of expressivity in the Abacus vs. Female Performer pairing were in Mid-ML and Low-TV participants (both moving from 60 percent before to 100 percent after the experience answering Female Performer as more expressive). These findings are visualized in the bottom left (ML) and top right (TV) parts of Figure 7.

It may be possible to extend this finding to more items in general. In the pairing of NAO vs. Wooden Hand, more participants answered that the NAO (which did appear in this study) was more expressive than the Wooden Hand (which did not appear in this study) after the performance. This can be seen in Figure 8. This difference from before the experience to after the experience was especially strong for the High-MV and High-ML participants, but was reflective of the overall change regardless of TL/TV/ML/MV levels. As the NAO's rating increased after participants' experience, items which appear in performative environments may be more likely to be rated highly in terms of expressivity. It may be counter-intuitive that technically trained participants were more likely to assess the NAO as less powerful or positive when compared with a wooden hand, but those with a technical background may understand that the NAO is effectively an elaborate toy that breaks often whereas the wooden hand has a human-like elegance that is not hampered by frequent falls and software failures.

\subsection{Movement and technology literacy and valence and self-evaluation of difficulty and success}

During the ratings of the systems they encountered both before and after the experience, participants answered 


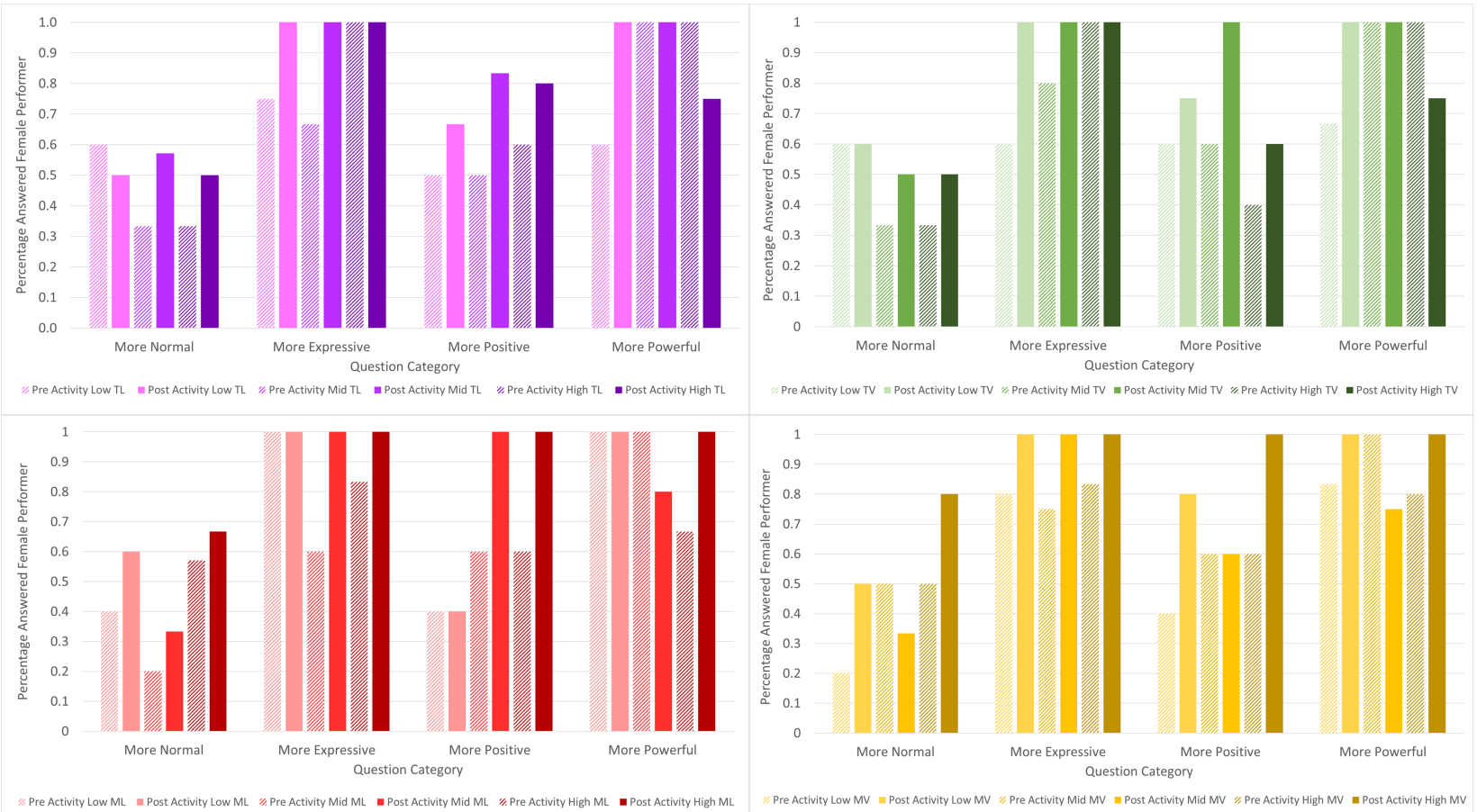

Figure 7: All pairings of Abacus vs. Female Performer, showing how many participants rated Female performer as more normal, more expressive, more positive, and more powerful. These are separated into three levels (Low, Mid, High) of four metrics (Technology Literacy, Technology Valence, Movement Literacy, and Movement Valence). All participants rated Female Performer as more expressive after the experience, regardless of metric category, which may support hypothesis that people who appear in performances are rated as more express (since the same ratings were not found for the Male vs. iPhone pairing). Additionally, Mid-ML and Low-TV participants showed the largest increase in answering Female Performer as more expressive after the experience (bottom left and top right figures here).
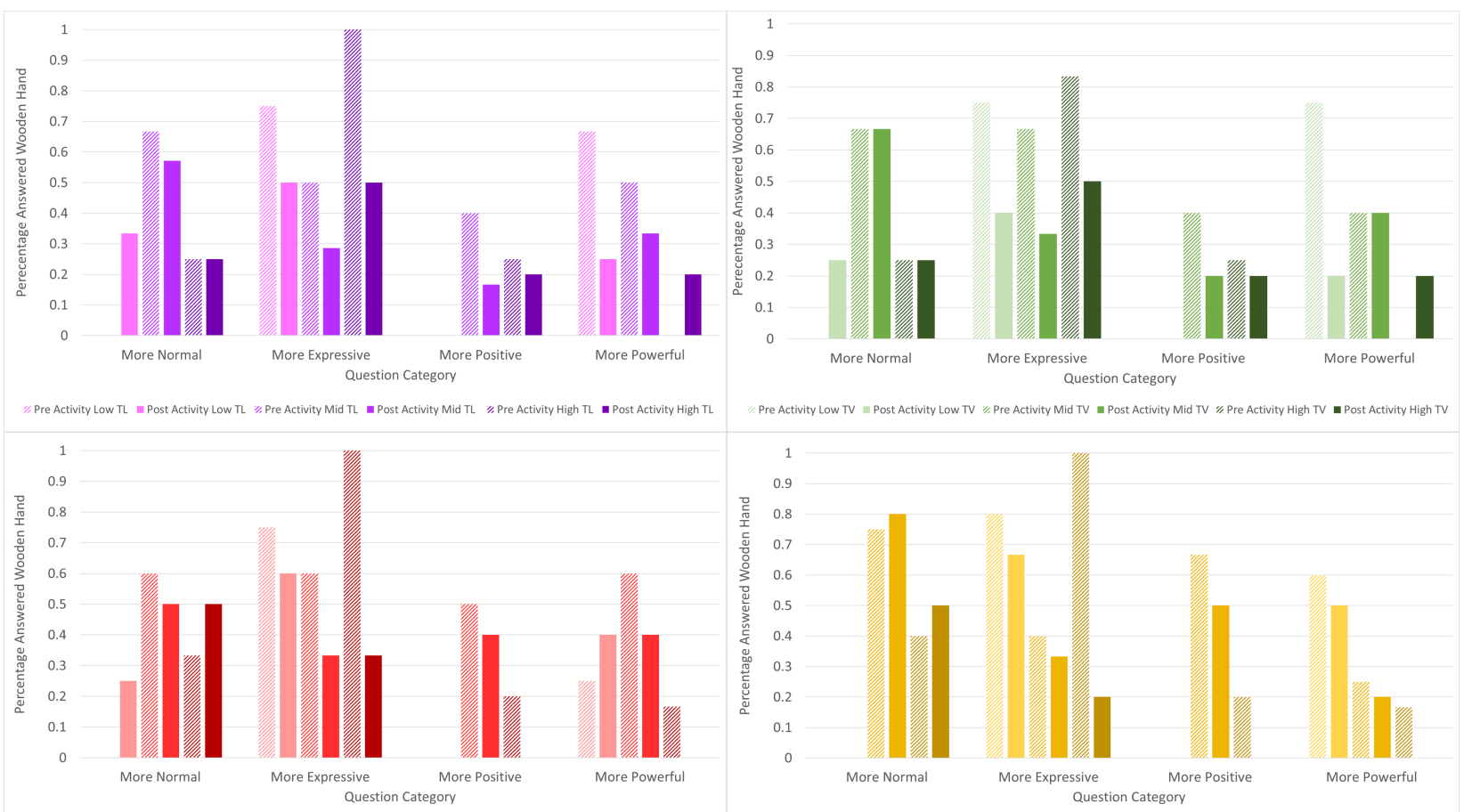

Figure 8: Side by side comparison question of the NAO robot and wooden hand in the pre and post-survey inquiring which one was more normal, more expressive, more positive, and more powerful. The NAO was rated more highly in terms of expressivity after participants experienced the installation, indicating that items which appear in performative environments are more likely to be rated highly in terms of expressivity. 
questions about the difficulty of matching the movement of each system as well as questions about their personal success at completing the mirroring task. This data was averaged together to create overall scores for each participant for a Predicted (before the experience) Difficulty score, a Predicted Success score, a Perceived (after the experience) Difficulty score, and a Perceived Success score.

Each participant's ML and MV scores were plotted as one point and then a linear regression line was applied to find the overall correlation relationship between participants' Literacy and Valence ratings. The same process was followed for TL and TV scores, finding the overall correlation relationship between these ratings. This data is shown in Figure 9. While a positive correlation was found between Literacy and Valence for both Movement and Technology, Movement had a slightly more positive relationship than Technology. This may be partially explained by the logic behind the question: if someone has a positive relationship between Literacy and Valence, that means that they feel very positive about the practices they do often. We found this to generally be the case for the movementbased questions, while sometimes the technology questions would not always have this positively linked relationship. For example, sometimes participants reported using their email daily or even hourly, but resented that they needed to do this.

The same process was followed to discover the relationship between Difficulty and Success, both before (Predicted) and after (Perceived) the experience. This data is shown in Figure 10. The Predicted and Perceived relationships were negatively correlated, with respective slopes of -0.397 and -0.520 . The slightly more negative relationship between Difficulty and Success for the Perceived category shows that after the experience, participants overall believed the task was a little more difficult and their success a little lower than they had predicted. Based on the qualitative feedback on the individual systems, this difference may have been largely due to the Avatar system. Participants did not predict beforehand that the Avatar would be floating at times or moving in more extreme ways, but after the experience, they reported feeling the task was "impossible due to physical limitation" or "because of gravity".

This data analysis was also insightful because it allowed for examination of outlier participants. The participant who was consistently an outlier on both Technology and Movement analysis here was more positive than the other participants for Movement and more negative than the other participants for Technology. Looking at some of the qualitative feedback from this outlier participant revealed a conflicted relationship with Technology. They mentioned that "some are my help," when asked to de- scribe how they felt about the technologies they used. They explained, mentioning that Roombas “don't get in my way and I love them. Some like FB change and get smarter without trying to help." When asked the same question about the movement practices they did, they answered these are about "carving time for myself, managing stress."

\subsection{Qualitative feedback}

Some notable information from the qualitative questions included reactions to the experience as well as potential titles for the experience. An expanded table can be found in Table 1 of the Appendix in Section 6. One participant described their experience, saying "It is easier to be a human as a human than to try to be a robot. We are used to moving within the confines of a normal day. This experience stretches you." Others described their experience as "immersive" and many reflected that this was a new experience to them, saying it was "like nothing I've ever done before - took me out of my comfort zone."

Some of the findings supported in the data could potentially be explained further by qualitative comments and could lead to future research to verify hypotheses about participants' reasoning behind their ratings. For example, as mentioned previously, the biggest differences for predicted success and final reported success self-evaluation were for the Avatar system. Participants' qualitative feedback provided information on how "the VR model didn't do natural movements" and that this agent "was impossible to imitate."

\section{Conclusions}

This paper presented a series of experiments that utilized live performance and an interactive installation to measure human perceptions of various agents. The results of this data collection show that items included within artistic installations are perceived differently before and after the installation experience. In particular, people were less likely to attribute the action of humanoid systems to human activity after experiencing the installation.

Additional data reveals that individuals' perceptions of various agents can vary based on the individual's movement and technology literacy and valence. Viewing the dataset through the lens of movement and technology literacy (two veins of experience that inform the movementbased experience inside the installation) further refines our analysis of experiencing, allowing us to identify par- 


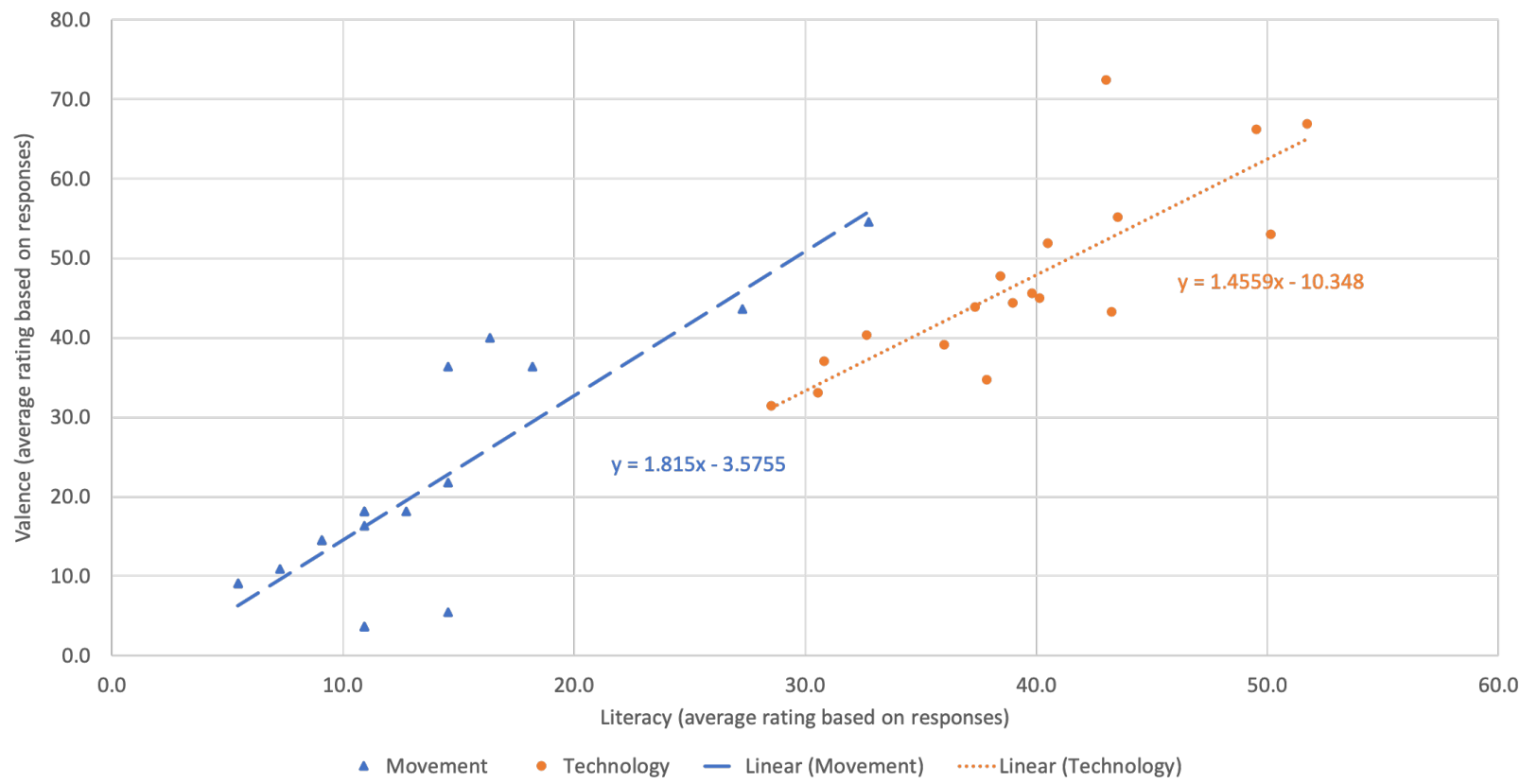

Figure 9: Each participant's Movement scores for Literacy and Valence plotted as one point (a blue triangle), as well as each participant's Technology scores for Literacy and Valence plotted as one point (an orange dot). The linear regression line for Movement and linear regression line for Technology applied. While both Movement and Technology show a positive correlation between Literacy and Valence, Movement has a slightly more positive relationship (with a slope of 1.815) than Technology (with a slope of 1.456). The average value for Movement Literacy was 13.4, Movement Valence was 20.8, Technology Literacy was 39.6, and Technology Valence was 47.3.

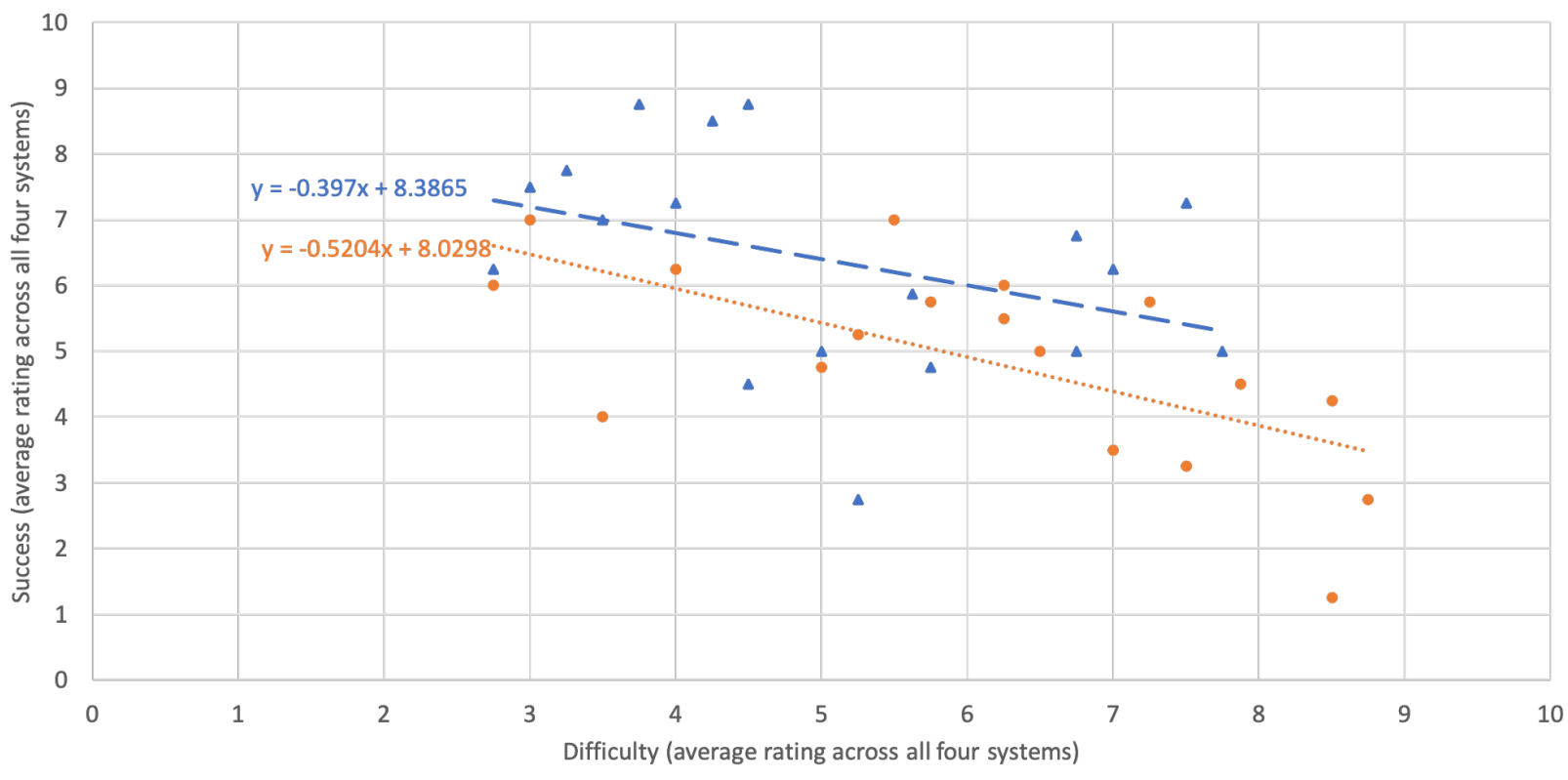

- Predicted Scores - Perceived Scores - Linear (Predicted Scores) …... Linear (Perceived Scores)

Figure 10: Each participant's average Predicted (before the experience) scores for Difficulty and Success plotted as one point (a blue triangle), as well as each participant's average Perceived (after the experience) scores for Difficulty and Success plotted as one point (an orange dot). The linear regression line for Predicted scores and linear regression line for Perceived scores applied. Both Predicted (with a slope of -0.397) and Perceived (with a slope of -0.5204) scores show a similarly negative relationship between Difficulty and Success. 
ticipants with extreme experiences as well as note how attitudes toward movement and technology change with additional exposure. Namely attitudes improve for both with increased exposure, but slightly more for movement experience than technology.

While the results of this analysis is promising, this was still an initial attempt at more comprehensively examining previous movement and technology experience, and a large amount of future work is needed to better design these metrics of TL, TV, ML, and MV, the questions asked, and how best to intentionally capture this information in an accurate and truly representative way.

Future work includes measuring other perceptive lenses, like power, valence, and acceptability. Additional design elements may be adjusted or employed in future installation iterations. We will continue to increase the size of populations that can experience this system through improvements to logistics, advertising, and resources, as an $\mathrm{N}=18$ is a small sample size. Further, we continue to refine the measurements we use to characterize participant experience - before and after the treatment inside this installation.

This work posed a sort of Turing Test to audience members, asking "What controls this agent?" and "Is it human?" Interestingly, audience members may have had less personal ambiguity about this question before they entered the installation. This initial work, then, has important impacts on how people view humanoid systems and what they think is controlling them. The fact that this installation was able to sway perceptions - in a direction away from the true structure - means that future anthropomorphic agents may also benefit from a similar bump. This influence needs to be characterized to ensure that the public is well-informed about the technology that may soon surround them.

\section{Acknowledgements}

This work was conducted under IRB \#17427 and supported by NSF grant \#1528036 and DARPA award \#D16AP00001. The authors thank Ishaan Pakrasi and Novoneel Chakraborty for co-creating this installation. The authors also thank producers at The Conference for Research on Choreographic Interfaces (CRCI) 2018 and The International Conference on Movement and Computing (MOCO) 2018. Special thanks to ThoughtWorks, ParadigmShift organizers, especially Andrew McWilliams, Jared Hatch, Zach Portilla, Matt Lewis, Katy Bond, and Mindset Brain Gym and Gallery for their presenting support. Additional thanks to Alexandra Bacula, Roshni Kaushi, Alexandra Nilles, Grace Gately, and Vanessa Conley for ushering this installation.

\section{References}

[1] F. Anstey, Vice versâ, or, A lesson to fathers, Smith, Elder, 1882, 1

[2] N. Tucker, Vice versa: The first subversive novel for children, Children's Literature in Education, 1987, 18(3), 39-147

[3] I. F. of Robotics, 31 million robots helping in households worldwide by 2019, tech. rep., International Federation of Robotics, https://ifr.org/ifr-press-releases/news/31-millionrobotshelping-in-households-worldwide-by-2019, 2016

[4] N. N. Television, Nielsen estimates 119.6 million tv homes, Nielsen Insights, 2017

[5] P. R. Center, Mobile fact sheet, Washington: Pew Research Center, 2018

[6] A. Steinfeld, et al., Common metrics for human-robot interaction, In: Proceedings of the 1st ACM SIGCHI/SIGART Conference on Human-Robot Interaction, ACM, 2006, 33-40

[7] C. Bartneck, D. Kulić, E. Croft, S. Zoghbi, Measurement instruments for the anthropomorphism, animacy, likeability, perceived intelligence, and perceived safety of robots, International Journal of Social Robotics, 2009, 1(1), 71-81

[8] B. Reeves, C. I. Nass, The media equation: How people treat computers, television, and new media like real people and places, Cambridge University Press, 1996

[9] C. Nass, Y. Moon, N. Green, Are machines gender neutral? Gender-stereotypic responses to computers with voices, Journal of Applied Social Psychology, 1997, 27(10), 864-876

[10] F. Eyssel, D. Kuchenbrandt, Social categorization of social robots: Anthropomorphism as a function of robot group membership, British Journal of Social Psychology, 2012, 51(4), 724-731

[11] F. Eyssel, F. Hegel, (S)he's got the look: Gender stereotyping of robots 1, Journal of Applied Social Psychology, 2012, 42(9), 2213-2230

[12] C. D. Kidd, C. Breazeal, Effect of a robot on user perceptions, In: Proceedings of the 2004 IEEE/RSJ International Conference on Intelligent Robots and Systems (IROS 2004), IEEE, 2004, 4, 3559-3564

[13] R. Tamagawa, C. I. Watson, I. H. Kuo, B. A. MacDonald, E. Broadbent, The effects of synthesized voice accents on user perceptions of robots, International Journal of Social Robotics, 2011, 3(3), 253-262

[14] M. Saerbeck, C. Bartneck, Perception of affect elicited by robot motion, In: Proceedings of the 5th ACM/IEEE International Conference on Human-Robot Interaction, IEEE Press, 2010, 53-60

[15] M. Heimerdinger, A. LaViers, Influence of environmental context on recognition rates of stylized walking sequences, In: A. Kheddar et al. (Eds.), Social Robotics, ICSR 2017, Lecture Notes in Computer Science, vol. 10652, Springer, Cham

[16] C. Bartneck, T. Nomura, T. Kanda, T. Suzuki, K. Kato, Cultural differences in attitudes towards robots, In: Proceedings of Symposium on Robot Companions (SSAISB 2005 Convention), 2005, $1-4$ 
[17] C. Bartneck, T. Suzuki, T. Kanda, T. Nomura, The influence of people's culture and prior experiences with Aibo on their attitude towards robots, Al \& Society, 2007, 21, 217-230

[18] J. Forlizzi, C. DiSalvo, Service robots in the domestic environment: a study of the Roomba vacuum in the home, In: Proceedings of the 1st ACM SIGCHI/SIGART Conference on Human-Robot Interaction, ACM, 2006, 258-265

[19] R. Hortensius, E. S. Cross, From automata to animate beings: The scope and limits of attributing socialness to artificial agents, Annals of the New York Academy of Sciences, 2018

[20] N. Suzuki, C. Bartneck, Subtle expressivity for characters and robots, In: CHI'03 Extended Abstracts on Human Factors in Computing Systems, ACM, 2003, 1064-1065

[21] C. Pelachaud, Studies on gesture expressivity for a virtual agent, Speech Communication, 2009, 51(7), 630-639

[22] T. Flemisch, A. Viergutz, R. Dachselt, Easy authoring of variable gestural expressions for a humanoid robot, In: Proceedings of the 2014 ACM/IEEE International Conference on Human-Robot Interaction, ACM, 2014, 328-328

[23] H. Knight, R. Simmons, Expressive motion with $x, y$ and theta: Laban effort features for mobile robots, In: The 23rd IEEE International Symposium on Robot and Human Interactive Communication, IEEE, 2014, 267-273

[24] A. Smith, M. Anderson, Automation in everyday life, Washington: Pew Research Center, 2017

[25] S. Ledbetter, America's top fears 2015, Chapman University Blog, 2015

[26] J. J. Bryson, The past decade and future of Al's impact on society, 2019

[27] K. Goldberg, R. Siegwart, Beyond Webcams: An introduction to online robots, MIT Press, 2002

[28] S. Miller, J. Van Den Berg, M. Fritz, T. Darrell, K. Goldberg, P. Abbeel, A geometric approach to robotic laundry folding, The International Journal of Robotics Research, 2012, 31(2), 249-267

[29] S. J. Burton, A.-A. Samadani, R. Gorbet, D. Kulić, Laban movement analysis and affective movement generation for robots and other near-living creatures, In: Dance Notations and Robot Motion, Springer, 2016, 25-48

[30] P. Gemeinboeck, R. Saunders, Creative machine performance: Computational creativity and robotic art, In: Proceedings of the Fourth International Conference on Computational Creativity (ICCC 2013), 2013, 215-219

[31] M. Egerstedt, T. Murphey, J. Ludwig, Motion programs for puppet choreography and control, In: A. Bemporad, A. Bicchi, G. Buttazzo (Eds.), Hybrid Systems: Computation and Control, HSCC 2007, Lecture Notes in Computer Science, vol 4416, Springer, Berlin, Heidelberg

[32] E. Jochum, J. Schultz, E. Johnson, T. Murphey, Robotic puppets and the engineering of autonomous theater, In: A. LaViers, M. Egerstedt (Eds.), Controls and Art. Springer, Cham, 2014, 107-128

[33] S. Nakaoka, A. Nakazawa, K. Yokoi, H. Hirukawa, K. Ikeuchi, Generating whole body motions for a biped humanoid robot from captured human dances, In: Proceedings of 2003 IEEE International Conference on Robotics and Automation (ICRA'03), IEEE, 2003, 3, 3905-3910

[34] P. Gemeinboeck, R. Saunders, Towards socializing nonanthropomorphic robots by harnessing dancers' kinaesthetic awareness, In: International Workshop in Cultural Robotics, Springer, 2015, 85-97
[35] A. LaViers, L. Teague, M. Egerstedt, Style-based robotic motion in contemporary dance performance, In: A. LaViers, M. Egerstedt (Eds.), Controls and Art, Springer, Cham, 2014

[36] E. Jochum, E. Vlachos, A. Christoffersen, S. G. Nielsen, I. A. Hameed, Z.-H. Tan, Using theatre to study interaction with care robots, International Journal of Social Robotics, 2016, 8(4), 457-470

[37] S. Bianchini, F. Levillain, A. Menicacci, E. Quinz, E. Zibetti, Towards behavioral objects: A twofold approach for a system of notation to design and implement behaviors in nonanthropomorphic robotic artifacts, In: J.P. Laumond, N. Abe (Eds.), Dance Notations and Robot Motion, Springer Tracts in Advanced Robotics, vol. 111, Springer, Cham

[38] F. B. Gilbreth, L. M. Gilbreth, Applied motion study: A collection of papers on the efficient method to industrial preparedness, Macmillan, 1919

[39] G. Johansson, Visual perception of biological motion and a model for its analysis, Perception \& Psychophysics, 1973, 14(2), 201-211

[40] W. H. Dittrich, Action categories and the perception of biological motion, Perception, 1993, 2(1), 15-22

[41] F. Loula, S. Prasad, K. Harber, M. Shiffrar, Recognizing people from their movement, Journal of Experimental Psychology: Human Perception and Performance, 2005, 3(1), 210

[42] B. R. Duffy, Anthropomorphism and the social robot, Robotics and autonomous systems, 2003, 42(3-4), 177-190

[43] T. Schiphorst, A case study of Merce Cunningham's use of the LifeForms computer choreographic system in the making of trackers, PhD thesis, Arts and Social Sciences: Special Arrangements, 1993

[44] M. Nyman, Experimental music: Cage and beyond, vol. 9. Cambridge University Press, 1999

[45] A. Schöllig, F. Augugliaro, R. D’Andrea, A platform for dance performances with multiple quadrocopters, In: Proceedings of the IEEE/RSJ International Conference on Intelligent Robots and Systems (IROS), Workshop on Robots and Musical Expressions, 2010, 1-8

[46] A. Schöllig, F. Augugliaro, R. D’Andrea, A platform for dance performances with multiple quadrocopters, Improving Tracking Performance by Learning from Past Data, 2012, 147

[47] H. Knight, R. Simmons, An intelligent design interface for dancers to teach robots, In: 2017 26th IEEE International Symposium on Robot and Human Interactive Communication (ROMAN), IEEE, 2017, 1344-1350

[48] N. T. Fitter, H. Knight, N. Martelaro, D. Sirkin, What actors can teach robots, In: Proceedings of the $2017 \mathrm{CHI}$ Conference Extended Abstracts on Human Factors in Computing Systems, ACM, 2017, 574-580

[49] L. Noy, E. Dekel, U. Alon, The mirror game as a paradigm for studying the dynamics of two people improvising motion together, In: Proceedings of the National Academy of Sciences, 2011, 108(52), 20947-20952

[50] P. Slowinski, E. Rooke, M. Di Bernardo, K. Tanaseva-Atanasova, Kinematic characteristics of motion in the mirror game, In: 2014 IEEE International Conference on Systems, Man, and Cybernetics (SMC), IEEE, 2014, 748-753

[51] C. Zhai, F. Alderisio, P. Slowinski, K. Tsaneva-Atanasova, M. di Bernardo, Modeling joint improvisation between human and virtual players in the mirror game, 2015, arXiv preprint arXiv:1512.05619 
[52] D. C. Reiizes, E. J. Mutran, M. E. Fernandez, Middle-aged working men and women: Similar and different paths to selfesteem, Research on Aging, 1994, 16(4), 355-374

[53] D. N. Smith, The relationship between academic major, selfesteem and body-esteem in nonclinical, undergraduate college women, PhD thesis, Georgia State University, 1995

[54] J. A. McMullin, J. Cairney, Self-esteem and the intersection of age, class, and gender, Journal of Aging Studies, 2004, 18(1), 75-90

[55] A. C. Keller, L. L. Meier, S. Gross, N. K. Semmer, Gender differences in the association of a high quality job and self-esteem over time: A multiwave study, European Journal of Work and Organizational Psychology, 2015, 24(1), 113-125

[56] S. Sprecher, J. E. Brooks, W. Avogo, Self-esteem among young adults: Differences and similarities based on gender, race, and cohort (1990-2012), Sex Roles, 2013, 69(5-6), 264-275

[57] P. Dijkstra, D. P. Barelds, O. van Brummen-Girigori, Weightinfluenced self-esteem, body comparisons and body satisfaction: Findings among women from the Netherlands and Curacao, Sex Roles, 2015, 73(7-8), 355-369

[58] C. Kontra, S. Goldin-Meadow, S. L. Beilock, Embodied learning across the life span, Topics in Cognitive Science, 2012, 4(4), 731-739

[59] G. Downey, 'Practice without theory': a neuroanthropological perspective on embodied learning, Journal of the Royal Anthropological Institute, 2010, 16, S22-S40

[60] R. Lindgren, M. Johnson-Glenberg, Emboldened by embodiment: Six precepts for research on embodied learning and mixed reality, Educational Researcher, 2013, 42(8), 445-452

[61] C. Cuan, I. Pakrasi, A. LaViers, Time to compile: An interactive art installation, Intersections: 16th Biennial Symposium, The Ammerman Center for Arts and Technology, 2018

[62] C. Cuan, I. Pakrasi, E. Berl, A. LaViers, CURTAIN and time to compile: A demonstration of an experimental testbed for humanrobot interaction, In: 2018 27th IEEE International Symposium on Robot and Human Interactive Communication (RO-MAN), IEEE, 2018, 255-261

[63] C. Cuan, I. Pakrasi, A. LaViers, Perception of control in artificial and human systems: A study of embodied performance interactions, In: International Conference on Social Robotics, Springer, 2018, 503-512

[64] C. Cuan, I. Pakrasi, A. LaViers, Time to compile, In: Proceedings of the 5th International Conference on Movement and Computing (MOCO'18), ACM, 2018 


\section{Appendix}

Table 1: Qualitative feedback

\begin{tabular}{|c|c|}
\hline Participant reaction, free response & Experience title \\
\hline Was neat seeing movement of robot. Confusion at some points. & Movement mirroring \\
\hline $\begin{array}{l}\text { It was a great experience. I am really bad at creating and mimicking movements and } \\
\text { today I got the same feeling and experience. I loved the moves with the real dancer. }\end{array}$ & Dance dance move \\
\hline $\begin{array}{l}\text { I felt more challenged by the artificial dancers as it seemed their limbs could move } \\
\text { more autonomously than mine or able to defy physics (like gravity)...I felt like I was } \\
\text { trying to be a mocap system. }\end{array}$ & MECAP \\
\hline It was cool! Made us giggle a bit. & Exbot \\
\hline $\begin{array}{l}\text { At first awkward and difficult but later enjoyably challenging. Creative feeling. Some } \\
\text { self-consciousness. }\end{array}$ & Robotic Creativity \\
\hline $\begin{array}{l}\text { It was quite interesting and outside of my comfort zone. Interesting to see how imi- } \\
\text { tation depends on what you are seeing it. }\end{array}$ & Attention to detail \\
\hline Immersive. & Interesting \\
\hline $\begin{array}{l}\text { It is easier to be a human as a human than to try to be a robot. We are used to moving } \\
\text { within the confines of a normal day. This experience stretches you. }\end{array}$ & $\begin{array}{l}\text { Moving: step by step } \\
\text { - with arms }\end{array}$ \\
\hline \multicolumn{2}{|l|}{ Reminded me of Tai Chi. } \\
\hline Exciting, scary, adoring the tiny eyes of the Small Robot. & Who is there? \\
\hline A lot of fun, more difficulty than anticipated. & Robot imitate human \\
\hline $\begin{array}{l}\text { Joyful. It was fun to realize that the whole thing was a feedback loop. (I think!) The } \\
\text { little robots were cute, and I enjoyed having an unmediated experience. }\end{array}$ & Robot Dance Shuffle \\
\hline $\begin{array}{l}\text { It's not what I would call dancing. The movements felt stiff and unnatural. They don't } \\
\text { exactly match the music. The music is calming and intriguing. The experience was in- } \\
\text { teresting as the medium affects the movement. It was easier to mimic some (like the } \\
\text { woman) rather than others as they are more visual/personal ones to try and predict } \\
\text { the likely next move. }\end{array}$ & $\begin{array}{l}\text { Learning to dance } \\
\text { naturally }\end{array}$ \\
\hline
\end{tabular}

I felt unsure of how to react at each segment - moving with the shadow robot and Dance of time human was easy and fun. It was interesting to see how small the robot was.

At the station with robot as a shadow, I felt I did relatively ok until I was realized Dancing surprises the robot was doing something else when I really saw him. Imitating the 3D version was more difficult. The robot on the screen frustrated me as it cannot possibly be imitated. I felt most comfortable with the person.

Like nothing l've ever done before. Interpretive - took me out of my comfort zone. Awareness Had trouble figuring out mirroring the movement so I had some delay in responding. Bodily translation The first one was hard to interpret and then it got easier with 2 nd and 3 rd. 
Table 2: Gender.

\begin{tabular}{c|c}
\hline Male & 9 \\
Female & 9 \\
\hline
\end{tabular}

Table 3: Education completed by participants.

\begin{tabular}{c|c}
\hline High School & 2 \\
Some College & 1 \\
Associate & 2 \\
Bachelor's & 7 \\
Master's & 5 \\
Doctorate & 1 \\
\hline
\end{tabular}

Table 4: Native language of participants.

\begin{tabular}{c|c}
\hline English & 10 \\
German & 2 \\
Spanish & 1 \\
Farsi & 1 \\
Vietnamese & 1 \\
Other(Unspecified) & 2 \\
\hline
\end{tabular}

Table 5: Country of origin.

\begin{tabular}{c|c}
\hline Australia & 1 \\
Canada & 7 \\
Dominican Republic & 1 \\
Germany & 3 \\
Iran & 1 \\
USA & 3 \\
\hline
\end{tabular}

Table 6: Age of participants.

\begin{tabular}{l|l}
\hline $18-24$ & 4 \\
$25-34$ & 4 \\
$35-44$ & 7 \\
$45-54$ & 2 \\
$55-64$ & 0 \\
$65-74$ & 1 \\
\hline
\end{tabular}

Table 7: Childhood home area.

\begin{tabular}{c|c}
\hline Rural & 1 \\
Suburban & 5 \\
Urban & 12 \\
\hline
\end{tabular}

